\title{
Odor-mediated double-alternation responding: A multiple-baseline reversal demonstration
}

\author{
ROBERT E. PRYTULA and SHARON M. LAWLER \\ Middle Tennessee State University, Murfreesboro, Tennessee 37130 \\ and \\ STEPHEN F. DAVIS \\ Austin Peay State University, Clarksville, Tennessee 37040
}

\begin{abstract}
In a four-phase study with rats serving as subjects, a multiple-baseline technique was used to assess the relationship between runway behavior and odor cues. The results show that behavior was controlled more by the cue property of odor than by memory.
\end{abstract}

Traditionally, the mediation of instrumental behaviors, such as running in the runway, responding in T- or Y-mazes, etc., has been attributed to such constructs as habit strength (Hull, 1952; Spence, 1956); memory (Spear, 1971; Capaldi, 1971); etc. Recently, there have been a number of new and disturbing developments in learning psychology that have posed serious questions for the traditional interpretations. Garcia, McGowan, and Green (1972), working with taste aversion, have shown that the rat is readily prepared to associate certain stimuli (sweet taste) with certain responses (illness-induced avoidance) and is prepared against associating others. Similarly, Bolles (1972) has found that species-typical defense responses are important mediators of instrumental avoidance learning. This and other literature (Reynierse, 1974) suggests that there exist within the rat certain evolutionary-adaptive responses. And these biological constraints appear to be more important determiners of behavior than such constraints as habit, memory, and reinforcement contingencies.

Runway research using single- (Amsel, Hug, \& Surridge, 1969) and double-alternation schedules of reward and nonreward appears to fit more under the biological constraints model than a memory model. Literature on double-alternation responding (Bloom \& Phillips, 1973: Davis, Prytula, Harper, Tucker, Lewis, \& Flood, 1974; Ludvigson, 1969; Ludvigson \& Sytsma, 1967; Pitt, Davis, \& Brown, 1973; Prytula \& Colbert, 1975; Prytula \& Davis, 1974; Seago, Ludvigson, \& Remley, 1970) has provided overwhelming evidence that a rat exudes an odor on the frustrative or nonreward trials, which can be utilized by subsequent subjects as a discriminative cue, allowing these subjects to forecast

This research was supported by a Faculty Research Grant from Middle Tennessee State University to the first author, and a Tower Fund Research Grant from Austin Peay State University to the third author.

Reprint requests should $\mid$ be directed to Robert E. Prytula, Department of Psychology:s, Middle Tennessee State University, Murfreesboro, Tenn. 37130. the nature of the goal event prior to entry. Although the evidence for a pheromone interpretation is indirect (see Mellgren, Fouts, \& Martin, 1973; Wasserman \& Jensen, 1969), this literature does suggest that the rat is prepared to respond to and utilize odor more so than other cues.

Although the studies cited have existed for some time in the literature, researchers using the discrete-trial apparatus have not employed the necessary procedural precautions for odor control. Because of this, the present authors felt that further convincing demonstrations were needed. Sidman (1960), Cook and Campbell (1975), and Risley and Wolf (1972) have suggested that one of the most powerful designs for demonstrating the effect of the independent variable is the multiple-baseline reversal technique. Therefore, the present study was designed to demonstrate, through the use of the multiple-baseline reversal design, the relationship between the cue properties of odor and running behavior in the runway.

\section{METHOD}

\section{Subjects}

Sixteen male albino rats, 90 days old at the beginning of pretraining, were purchased from the Holtzman Co., Madison, Wisconsin, and served as subjects. Eleven days prior to the start of the experiment proper, the subjects were placed on a food deprivation schedule which maintained them at $85 \%$ ad lib. body weight. Water was continuously available in the home cage.

\section{Apparatus}

The apparatus (more fully described in Prytula \& Colbert, 1975) was a gray wooden runway $152.4 \mathrm{~cm}$ long, $9.16 \mathrm{~cm}$ wide, and $16.51 \mathrm{~cm}$ high. A $30.48 \mathrm{~cm}$ start segment was separated from an $88.90 \mathrm{~cm}$ run segment by a frosted Plexiglas door. In the goal segment, a second guillotine door separated the run segment from a $30.48 \mathrm{~cm}$ goal box. The entire apparatus was floored with $1 / 4$-in. hardware cloth and was covered with clear Plexiglas lids. Running underneath the entire runway was a U-shaped metal tunnel forming an odorexhaust duct. Located and recessed $22.86 \mathrm{~cm}$ beyond the goal segment was a small, exceptionally quiet fan continuous with the tunnel forming the odor-exhaust system. 


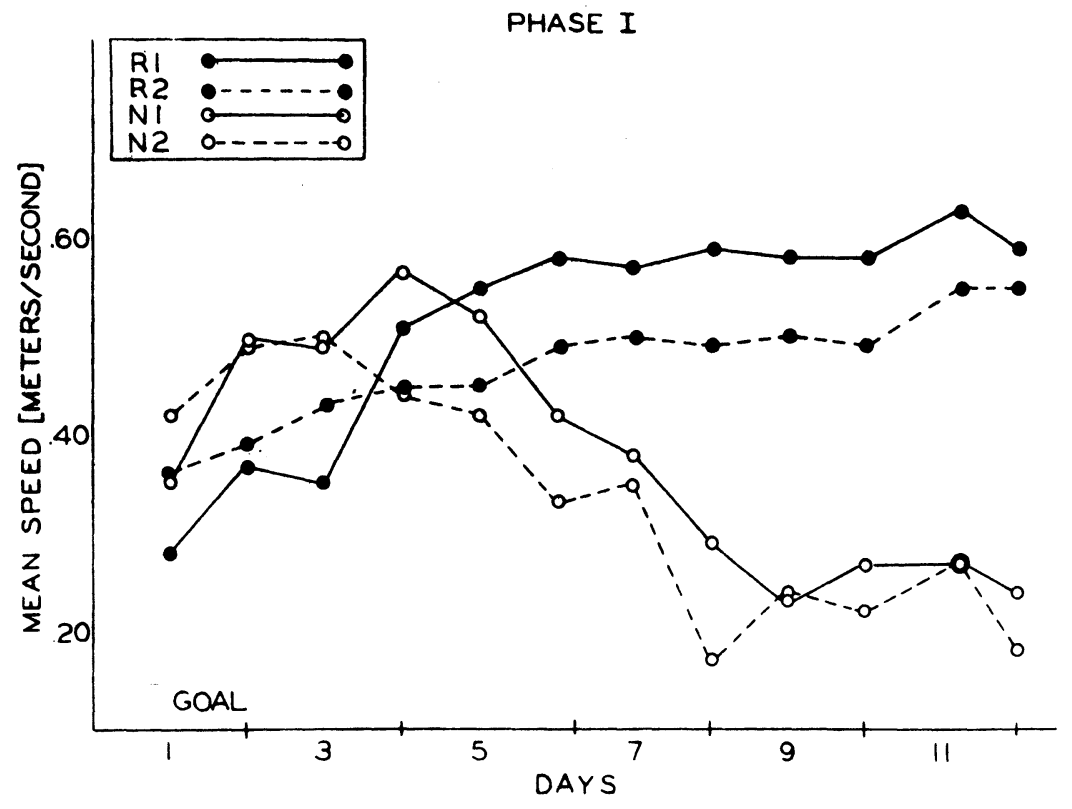

Figure 1. Mean speeds $(\mathrm{m} / \mathrm{sec})$ during Phase I. Each data point represents an average of the first two rewarded trials, the first two nonrewarded trials, etc.

\section{Procedure}

Two days prior to the beginning of the experimental phases, each subject received two pretraining trials. Pretraining consisted of $5 \mathrm{~min}$ of free exploration of the apparatus with two $300-\mathrm{mg}$ Noyes pellets available in both the goal area and the home cage. During these trials, all photoelectric and exhaust equipment was operative.

The experiment proper consisted of four phases. During Phase I each subject received eight trials a day for 12 days according to the following schedule: $R_{1} R_{2} N_{1} N_{2} R_{3} R_{4} N_{3} N_{4}$. On the rewarded (R) trials, the subject received two $300-\mathrm{mg}$ pellets and was removed immediately upon consuming the pellets; on the nonrewarded trials $(\mathrm{N})$, the subject was confined to the goal area for $30 \mathrm{sec}$. During all phases of the experiment all subjects received Trial 1 before Trial 2 was administered, etc. The order of running subjects was randomly determined at the inception of the experiment proper and remained constant for the duration of the experiment.

Throughout all phases of the experiment only one condition was varied: the exhaust-odor conditions in the runway. During Phase I, the exhaust fan was blocked and running for all eight trials while the subjects were in the alley, and remained closed between subjects. During Phase II (40 trials), the first four trials $\left(R_{1} R_{2} N_{1} N_{2}\right)$ for each and every subject were run with the exhaust fan condition open; the last four trials $\left(R_{3} R_{4} N_{3} N_{4}\right)$ were run with the fan blocked. During Phase III the exhaust fan conditions employed in Phase II were reversed (i.e., the first four trials were run under the blocked condition while the last four trials were run under the open condition). An extinction phase immediately followed Phase III. At the completion of Phase III, the subjects were randomly assigned to one of two groups, with half of the subjects being extinguished with the fan open, and the other half being extinguished with the fan closed. During extinction all subjects received eight trials each day for a three-day period. The confinement duration on each trial was $30 \mathrm{sec}$.

\section{RESULTS}

Start, run, and goal latencies for each subject were transformed to reciprocals, and when multiplied by the appropriate constant yielded speed scores in meters per second. Usually the speed score of Trial $R_{1}$ is combined with that of $R_{3}$ thus yielding an $R_{1}$ score; $R_{2}$ with $R_{4}$ yielding an $\mathbf{R}_{\mathbf{2}}$ composite score, etc. (see Seago et al., 1970). Because of the unique design employed in the present study, Trials $R_{1}$ and $R_{2}$ were combined to yield the $R_{1}$ composite; $N_{1}$ was combined with $N_{2}$ to yield an $\mathrm{N}_{1}$ composite, etc. These transformed scores for Phases I, II, and III were subjected to a Treatment (R-N) by Treatment (Days) by Subjects analysis of variance. ${ }^{1}$ A Groups (exhaust vs. nonexhaust) by Days analysis of variance was used to analyze the Phase IV (Extinction) results. Tukey's procedure was used for all significant contrasts.

Since the results of the run and goal measures were virtually identical, only the goal measure will be presented.

\section{Phase I}

The results of Phase I, Days 8 through 12, showed that when the subjects received their reward and nonreward events under the odor-intensified (fan blocked) condition they approached the goal [R-N, $F(3 / 42)=44.10, p<.001]$ significantly faster on the rewarded trials than on the nonrewarded trials (all ps $<.01$; see Figure 1).

Other comparisons showed that the subjects ran significantly faster on Trial $R_{1}$ than on Trials $N_{1}, R_{2}$, and $\mathrm{N}_{2}$; also speed on Trial $R_{2}$ was faster than on Trials $\mathrm{N}_{1}$ and $\mathrm{N}_{2}$ (all ps <.01).

\section{Phase II}

When odors were evacuated on the first four trials (fan open condition) there was an immediate increase in speed on Trial $\mathrm{N}_{1}$ in the goal measure [R-N, $\mathrm{F}(3 / 42)=82.20, \quad \mathrm{p}<.001 ;$ and $\mathrm{R}-\mathrm{N}$ by Days, $F(12 / 168)=6.49, p<.001]$. As can be seen from 
Figure 2, the subjects now ran faster on Trials $R_{1}, N_{1}$, and $R_{2}$ than on Trial $N_{2}$ (all ps $<.01$ ). This increase in speed observed on Trial $\mathrm{N}_{1}$ from Day 12, Phase I to Day 1, Phase II represents a change within two trials that effectively negates the past reinforcement history and consequent memory of 96 trials.

Other comparisons showed that, overall, Trials $\mathbf{R}_{\mathbf{1}}$ and $R_{2}$ were not significantly different; analysis of the R-N by Days interaction showed that by Day 5 the speed of approach on Trial $R_{2}$ was slower than on Trial $\mathrm{R}_{1}(\mathrm{p}<.01)$.

\section{Phase III}

Following Phase II, the exhaust-system conditions were reversed. This brought about an immediate reversal in speed on Trials $N_{1}$ and $N_{2}(p s<.01)$. The subjects immediately slowed down on Trial $\mathrm{N}_{1}$, while on Trial $\mathrm{N}_{2}$ there was an abrupt increase in speed (see Figure 2). This effect was more pronounced in the goal measure [R-N, $\mathrm{F}(3 / 42)=71.47, \mathrm{p}<.001 ;$ Days, $\mathrm{F}(4 / 56)=9.81$, $\mathrm{p}<.001 ;$ and R-N by Days, $\mathrm{F}(12 / 168)=4.69$, $\mathrm{p}<.001$ ] than in the run segment.

Analysis of the R-N by Days interaction (see Figure 2) showed that on Days 1 and 2 the speeds on Trials $\mathrm{N}_{2}$ and $R_{2}$ were similar. However, by Day 3 there was significant separation among the four trials (all ps $<.01)$.

As observed under the Phase II conditions, it appeared during Phase III that the previous 136 trials had little effect on the persistence of behavior under the exhaust condition. Similarly, the 40 exhaust trials of Phase II had little effect upon the Phase III behavior. ${ }^{2}$

\section{Phase IV}

As can be seen from the extreme right portion of Figure 2, there was a trend for the subjects to extinguish faster under the nonexhaust condition. In the run measure, Analysis of the Groups by Days interaction, $[F(2 / 28)=3.37, p<.05]$, showed that on the first two days of extinction, subjects in the exhaust group were more resistant to extinction than under the nonexhaust condition.

\section{DISCUSSION}

The results of the present study appear to be in agreement with previously reported odor data (e.g., Bloom \& Phillips, 1973; Davis et al., 1974; Ludvigson \& Sytsma, 1967; Pry tula \& Davis, 1974; Seago et al., 1970) in that alternating behavior was firmly established in the goal segment under the fan-odor conditions of Phase I. The subjects, during this phase, approached the goal area approximately three times faster on the $R$ as opposed to the $N$ trials.

Evacuating odors on the first four trials (Phase II) led to an immediate increase in speed on Trial $\mathrm{N}_{1}$ and a disruption of the patterning response on those trials. Trial $\mathrm{N}_{2}$ was unaffected, i.e., speed on this trial was similar to that observed on Phase I. With the reversal on fan-odor conditions (Phase III) there was an immediate reversal in speed on Trials $\mathrm{N}_{1}$ and $\mathrm{N}_{2}$; the subjects now approached the goal significantly slower on Trial $N_{1}$ while running fast on Trial $\mathrm{N}_{2}$. Thus, the results of Phases I, II, and III showed that there was a lawful relationship between observed behavior and the manipulated fan (i.e., odor) conditions. Specifically, when odors on the $\mathbf{N}$ trials were minimized the subjects were no longer able to discriminate the schedules and therefore ran fast. However, when the odors were maximized the subjects ran significantly slower, indicating that they were able to discriminate that portion of the schedule. More importantly, we have shown that portions of the patterned-response can be disrupted while others are left intact. This data appears to be in agreement with several recent studies (e.g., Bloom \& Phillips, 1973; Pitt et al., 1973; Prytula \& Cox, 1975; Seago et al., 1970) that have shown that rats do not appear to learn this schedule on the basis of memory alone. This literature suggests that in order for the rat to respond appropriately there must be some external cue, such as odor from preceding subjects, a light cue, etc., (see also Davis et al., 1974; Prytula \& Davis, 1974).

At this point one might attribute the observed effects to such

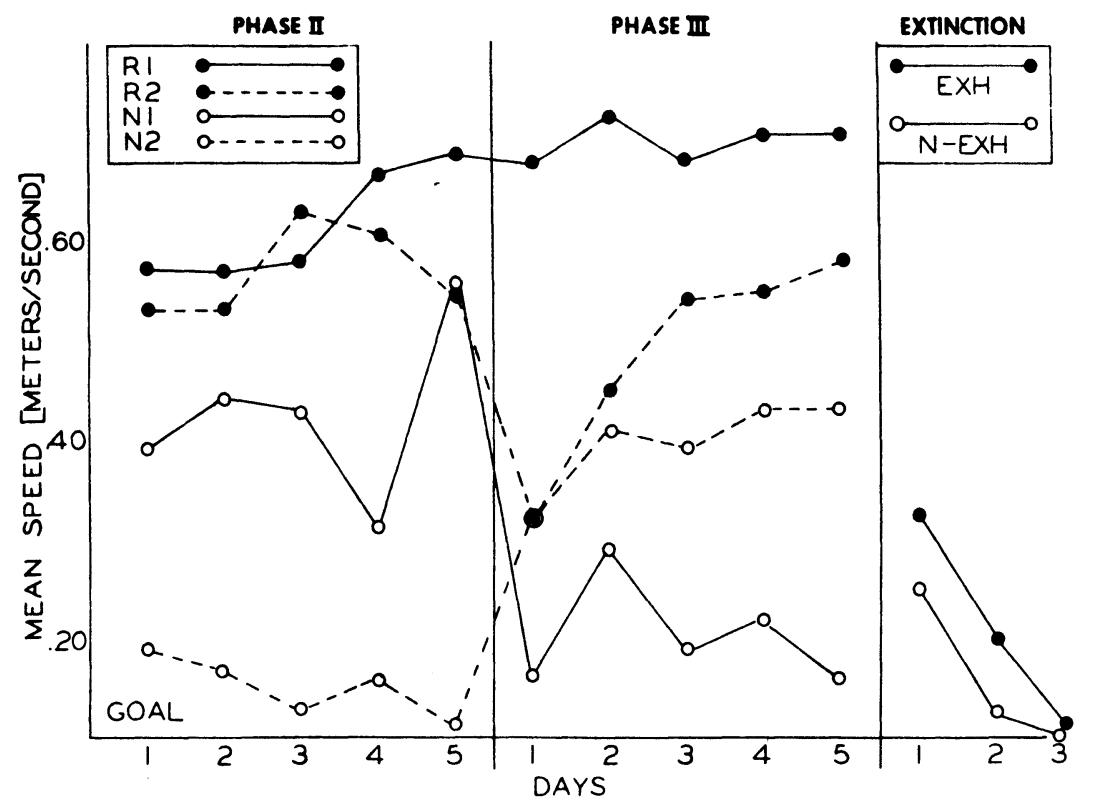

Figure 2. Mean speeds (m/sec) during Phases II, III, and IV. During Phases II and III each data point represents an average of the first two rewarded trials, the first two nonrewarded trials, etc. During Phase IV, each data point represents an average of eight trials. 
factors as differential effects produced by sound and air movements under the fan-blocked, as compared with the unblocked, condition. The following several points appear to mitigate against acceptance of these hypotheses: (1) with the change of the fan conditions from Phase I to Phase II, one would have a generalization decrement; this was not obtained, speed on Trial $\mathrm{N}_{1}$ was enhanced (a stimulus generalization increment?); (2) the change in the fan conditions leead to an immediate change (within two trials); (3) since the sound and air movement of the exhaust and nonexhaust conditions were contingently paired with both reward and nonreward, these cues should have been ineffective determinants: (4) Seago et al. (1970) have demonstrated that odor increasingly accumulates as a function of the number of subjects within the group, and as a result of this, subjects become progressively slower as a function of their position within the group (e.g., the first subject is usually the fastes, the last subject the slowest). In the present study, this general position effect was obtained under the nonexhaust conditions, but was virtually nonexistent under the exhaust conditions, and (5) Bloom and Phillips (1973) have found similar effects when odors were evacuated between trials.

Finally, the present experiment and that of Prytula and Colbert (1975) demonstrate that the within-subject, multiple-baseline reversal design can be utilized in the discrete-trial situation. Besides economy of subjects, it is a very powerful design for the assessment of independent variable effects (Wood. 1974).

\section{NOTES}

1. Since the goal events for Subject 1 were uncorrelated with subsequent subjects, his scores were not included in the analyses of Phases I, II, and III (see Ludvigson \& Sytsma, 1967).

2. Independent analysis of the goal measure, Day 12 (Phase I) with Day 1 (Phase II); Day 5 (Phase II) with Day 1 (Phase III) showed that $\mathrm{R}-\mathrm{N}$ by Days interaction was significant. Multiple mean comparisons confirmed the graphical impressions.

\section{REFERENCE NOTE}

Cook, T. D, \& Campbell, D. T. The design and conduct of quasi-experiments and true experiments in field settings. Unpublished manuscript. Northwestern University, 1975.

\section{REFERENCES}

Amsel, A. Hug, J. J., \& Surridge, C. T. Subject to subject trial sequence, odor trails, and patterning at 24-h ITI. Psychonomic Science, 1969, 15, 119-120.

Bloom, J. M., \& Phillips, J. M. Conspecific odors as discriminative stimuli in the rat. Behavioral Biology, 1973, 8, 279-283.
Bolles, R. C. Species-specific defense reactions and avoidance learning. In M. E. P. Seligman \& J. L. Hager (Eds.), Biological Boundaries of learning. New York, Appleton-Century-Crofts, 1972, 189-211.

Capaldi, E. J. Memory and learning: A sequential viewpoint. In W. K. Honig \& P. H. R. James (Eds.), Animal memory. New York and London: Academic Press, 1971, 111-154.

Davis, S. F., Prytula, R. E., Harper, W. E., Tucker, H. K., Lewis, C., \& Flood, L. Double-alternation runway performance as a function of inter- and intra-reinforcement odor cues. Psy chological Reports, 1974, 35, 787-793.

Garcia, J.. McGowan, B. K., \& Green, K. F. Biological constraints on conditioning. In M. E. P. Seligman \& J. L. Hager (Eds.), Biological boundaries of learning. New York: Appleton-Century-Crofts, 1972, 21-43.

Hull, C. L. A behavior svstem. New Haven, Conn.: Yale University Press, 1952

Ludvigson, H. W. Runway behavior of the rat as a function of intersubject reward contingencies and constancy of daily reward schedule. Psy chonomic Science, 1969, 15, 41-43.

Ludvigson, H. W., \& Sytsma, D. The sweet smell of success: Apparent double alternation in the rat. Psy chonomic Science, $1967,9,283-284$.

Mellgren, R. L., Fouts, R. S., \& Martin, J. W. Approach and escape to conspecific odors of reward and nonreward. Animal Learning \& Behavior, 1973, 1, 129-132.

Pitt, S., Davis, S. F., \& Brown, B. R. Apparent double alternation in the rat: A failure to replicate. Bulletin of the Psy chonomic Society, 1973, 2, 359-361.

Prytula, R. E., \& Colbert, J. C. Administration of trials within-Ss and double-alternation responding: A demonstration of a multiple baseline reversal. Psychological Reports, 1975, 36, $131-137$.

Prytula, R. E., \& Davis, S. F. Runway performance as a function of positively and negatively correlated olfactory cues. Psychological Reports, 1974, 35, 735-740.

Reynierse, J. H. Communication elements constraining animal learning and performance. In $L$. Krames, $P$. Pliner, \& $T$. Alloway (Eds.), Nonverbal communication, New York and London: Plenum Press, 1974.

Risley, T. R., \& Wolf, M. M. Strategies for analyzing behavioral change over time. In J. Nesselbroade \& H. Reese (Eds.), Life-span development psychology: Methodological issues. New York: Academic Press, 1972.

Seago, J. D., Ludvigson, H. W., \& Remley, N. R. Effects of anosmia on apparent double-alternation in the rat. Journal of Comparative and Physiological Psychology, 1970, 71, 435-442.

Sidman, $M$. T'actics of scientific research. New York: Basic Books, Inc., 1960.

Spear, N. E. Forgetting as retrieval failure. In W. K. Honig \& P. H. R. James (Eds.), A nimal memory New York and London, Academic Press, 1971, 45-109.

Spence, K. W. Behavior theory and conditioning. Englewood Cliff, New Jersey: Prentice-Hall, 1956.

Wasserman, E. A., \& Jensen, D. D. Olfactory stimuli and the "pseudo-extinction" effect. Science, 1969, 166, 1307-1309.

Wood, G. Fundamentals of psychological research. Boston: Little, Brown and Company, 1974. Pp. 101-103.

(Received for publication May 9,1975.) 